\title{
Polymeric Nanosuspensions for Enhanced Dissolution of Water Insoluble Drugs
}

\author{
Roya Yadollahi, ${ }^{1}$ Krasimir Vasilev, ${ }^{1,2}$ Clive A. Prestidge, ${ }^{3}$ and Spomenka Simovic ${ }^{3}$ \\ ${ }^{1}$ Mawson Institute, University of South Australia, Mawson Lakes, SA 5095, Australia \\ ${ }^{2}$ School of Engineering, University of South Australia, Mawson Lakes, SA 5095, Australia \\ ${ }^{3}$ Ian Wark Research Institute, University of South Australia, Mawson Lakes, Adelaide, SA 5095, Australia
}

Correspondence should be addressed to Spomenka Simovic; spomenka.simovic@unisa.edu.au

Received 2 August 2013; Accepted 1 September 2013

Academic Editor: Haifeng Chen

Copyright (C) 2013 Roya Yadollahi et al. This is an open access article distributed under the Creative Commons Attribution License, which permits unrestricted use, distribution, and reproduction in any medium, provided the original work is properly cited.

\begin{abstract}
The aim of the present research is to formulate and evaluate polymeric nanosuspensions containing three model water insoluble drugs, nifedipine (NIF), carbamazepine (CBZ), and ibuprofen (IBU) with various physicochemical properties. The nanosuspensions were prepared from hydroxypropyl methylcellulose (HPMC) and polyvinylpyrrolidone (PVP) by a cosolvent technique with polyethylene glycol (PEG-300) and water as the cosolvents. Physicochemical and morphological characteristics of the nanosuspensions (particle size, polydispersity index, and crystallinity) have been correlated with the drug release behaviour. The effects of polymer, drug ratio on the physical, morphological, and dissolution characteristics of the drugs are reported. Drug release is significantly enhanced from the nanosuspensions; for example, the maximum NIF, IBU, and CBZ concentrations after 8hour dissolution are increased approximately 37,2, and 1.2 times, respectively, in comparison with the pure powdered drugs. Based on this solubilization enhancement performance, the nanosuspensions have potential for increasing the orally dosed bioavailability of NIF, IBU, and CBZ.
\end{abstract}

\section{Introduction}

More than $40 \%$ of new chemical entities (NCE) are water insoluble compounds which currently make up $1 / 3$ of the United States Pharmacopeia recognised drugs [1, 2]. Water insoluble compounds (BCS Class II) have poor aqueous solubility and imperfect dissolution, which causes their low bioavailability [3]. Generation of drug nanosuspensions presents one solution to delivery of water insoluble drugs. Nanosuspensions have been defined as drug carriers with particle size range within $10-1000 \mathrm{~nm}$ [4]. Therefore, formulating new dosage forms to achieve adequate bioavailability has become a serious and challenging scientific, industrial, and medical issue. Water insoluble drugs are typically formulated with the help of various excipients whose aim is to improve drug dissolution rate and storage stability. Interaction of reactive functional groups of excipients with the drug molecules increases active surface area and consequently dissolution rate [5]. The use of excipients in formulations of insoluble drugs has proven ability to increase drug dissolution rate, but limitations such as toxicity of some surfactant compounds and limited drug loading have been identified [6]. According to the Noyes-Whitney equation, smaller particle size with higher surface area in contact with biological media leads to an enhanced drug dissolution rate $[7,8]$. Hence, scaling down convention drug powders to nanoparticles enhances drug solubility and bioavailability. Nanosuspensions can be prepared by different methods such as high pressure homogenization and media milling. However these techniques have drawbacks such as contamination of final products, broad particle size distributions, and the need for high energy input $[9,10]$. The co-solvent technique has been extensively used to prepare in situ nanosuspensions [11-17] and has numerous advantages over evaporation or heating-cooling techniques, such as being fast and easy to perform and suitable for thermolabile compounds.

The aim of this work is to explore solid-state and dissolution characteristics of polymeric nanosuspensions prepared by a co-solvent technique. Water insoluble drugs nifedipine (NIF), carbamazepine (CBZ), and ibuprofen (IBU) with 
different physiochemical properties (Table 1) were selected and used in realistic extended release doses. Commonly used pharmaceutical polymers hydroxypropyl methylcellulose (HPMC) and polyvinylpyrrolidone (PVP) were used as stabilisers/crystal growth inhibitors [18-21]. In addition to crystal inhibition, the HPMC polymer acts as a hydrophilic matrix agent which forms a strong viscous gel in contact with aqueous media, facilitating extended drug release [22]. The influence of polymer:drug ratio on nanoparticle formation, drug stabilization, and dissolution characteristics were explored. Drug crystallinity and polymorphic forms in nanosuspension polymeric matrices consisting of different polymers ratio were investigated using differential scanning calorimetry (DSC). The molecular structure and specifications of model drugs (nifedipine, carbamazepine, and ibuprofen) and excipients (mannitol, PEG-300, HPMC, and PVP) which were used in this study are presented in Table 1.

\section{Materials and Method}

2.1. Materials. High-purity (Milli-Q) water was used throughout the study ( $\mathrm{ph}=6.5 \pm 0.5)$. PEG-300 (Sigma Aldrich, Australia) was used as the co-solvent. Hydroxypropyl methylcellulose (HPMC) containing 28-30\% methoxyl and 7-12\% hydroxypropyl content, polyvinylpyrrolidone (PVP), and mannitol: $\geq 98 \%$ (SigmaAldrich) were used as received. Model drugs (NIF: $\geq 98 \%$ TLC, CBZ: $\geq 98 \%$ TLC, IBU: $\geq 98 \%$ GC) and phosphate buffer $(\mathrm{pH}=7.4)$ were also purchased from Sigma-Aldrich.

2.2. Preparation of Nanosuspensions. Nanosuspensions of model drugs were prepared by the co-solvent technique [30]. This technique includes mixing of two different phases. The first phase (organic phase) is PEG-300 with dissolved model drugs (NIF: $30 \mathrm{mg}, \mathrm{CBZ}: 400 \mathrm{mg}$, IBU: $400 \mathrm{mg}$ dissolved in 5 gr of PEG-300). The second phase (aqueous phase) where the model drugs are almost insoluble contains dissolved polymers (HPMC \& PVP) (Table 2). The two phases were sonicated for 2 hours. Upon subsequent addition of mannitol $(10 \% \mathrm{w} / \mathrm{v})$, the system was additionally sonicated for 2 hours.

2.3. Freeze Drying/Lyophilization and Redispersibility of Nanosuspensions. Nanosuspension formulations were lyophilized using mannitol as cryoprotectant. The freeze drying (Alpha 1-2 LDplus) was performed at a temperature of $-70^{\circ} \mathrm{C}$ and vacuum 0.09 mbar for 72 hours. The redispersibility of lyophilized samples was investigated by manual shaking of $5 \mathrm{mg}$ in glass vial with $20 \mathrm{~mL}$ PBS $(\mathrm{pH}=7.4)$. Formation of aggregates or precipitates was monitored visually.

2.4. Particle Size Analysis. Size and polydispersity index (the width of particle size distribution) of nanosuspensions were measured with dynamic light scattering (Zetasizer Nano ZS, Malvern Instruments, Ltd.). Refractive index values of PBS: $\mathrm{pH}=7.4(1.33)$ as the continuous phase and HPMC/PVP polymers with refractive index value of 1.45 were used in the size measurements. Nanosuspensions were diluted 1:100 in PBS $(\mathrm{pH}=7.4)$ and measured in the specified cuvettes at $23 \pm 0.5^{\circ} \mathrm{C}$ in triplicate.

2.5. Differential Scanning Calorimetry (DSC). Differential scanning calorimetric (DSC) analysis was carried out using TA Instruments model 2920. Samples (5-10 mg) were heated under nitrogen atmosphere on an aluminium pan at a rate of $10^{\circ} \mathrm{C} / \mathrm{min}$ over the temperature range of 25 and $300^{\circ} \mathrm{C}$. An empty pan of the same type was utilized as the reference. DSC thermograms were obtained by using TA universal analysis software. Calibrations of temperature and heat flow were performed with indium.

2.6. In Vitro Release Study. In vitro release of model drugs from nanosuspensions was studied for 8 hours using Vankel USP apparatus type 2 (paddle method) at the rotation speed of $50 \mathrm{rpm}$ and $900 \mathrm{~mL}$ of phosphate buffer $(\mathrm{pH}=7.4)$ as a dissolution medium. The dissolution test was thermoregulated at $37 \pm 0.5^{\circ} \mathrm{C}$. Sample aliquots of $4 \mathrm{~mL}$ were withdrawn from the receptor chamber at determined time intervals $(0.5,1,2,3,4,5,6,7$, and 8 hours $)$ and replaced with fresh buffer medium. The aliquots were then filtered through a Millipore membrane filter $(0.45 \mu \mathrm{m})$. The concentrations of NIF, IBU, and CBZ in the samples were analysed spectrophotometrically at a wavelength of 234, 263, and $283 \mathrm{~nm}$, respectively.

2.7. Kinetics of Drug Release. In order to investigate the drug release mechanism, in vitro release data were fitted by the following equations [31].

(a) Consider zero-order release:

$$
Q=Q_{0}+K_{0} t
$$

where $Q$ is the amount of drug dissolved at particular time, $t, Q_{0}$ is the initial amount of drug in solution at $t=0$, and $K_{0}$ is the zero-order release constant.

(b) Consider first-Order release:

$$
\ln Q=\ln Q_{0}+K_{1} t
$$

where $K_{1}$ is the first order release constant.

(c) Consider Hixson-Crowell cube root release:

$$
Q^{1 / 3}=Q_{0}^{1 / 3}-K_{c} t
$$

where $K_{c}$ is the cube root law release constant. 
TABLE 1: Characteristics of model water insoluble drugs (NIF, CBZ, and IBU) and excipients (HPMC, PVP, PEG-300, and mannitol) used in this study.

\begin{tabular}{|c|c|}
\hline Name and characteristics & Structure \\
\hline $\begin{array}{l}\text { Nifedipine } \\
\text { Dimethyl 2,6-dimethyl-4-(2-nitrophenyl)-1,4- } \\
\text { dihydropyridine-3,5-dicarboxylate } \\
\text { Appearance: a yellow crystalline powder } \\
\text { Molecular weight: } 346.3 \\
\text { Solubility: practically insoluble in water, sparingly in } \\
\text { dehydrated alcohol, freely in acetone } \\
\text { Indication: calcium channel blocker [23] } \\
\text { Log P: } 2.2[24] \\
\text { Solubility in PBS (pH 7): } 0.0056 \text { g/L [25] }\end{array}$ & \\
\hline $\begin{array}{l}\text { Carbamazepine } \\
5 \mathrm{H} \text {-dibenzo[b,f]azepine-5-carboxamide } \\
\text { Appearance: a white crystalline powder } \\
\text { Molecular weight: } 236.3 \\
\text { Solubility: practically insoluble in water, soluble in } \\
\text { alcohol and acetone } \\
\text { Indication: anticonvulsant and mood-stabilizing [23] } \\
\text { Log } P: 2.67 \text { [26] }\end{array}$ & \\
\hline $\begin{array}{l}P V P \\
\text { Molecular weight: } 29000 \\
\text { Specifications: improving the wettability, dissolution } \\
\text { rate, and crystal inhibitor }[20,21,27]\end{array}$ & \\
\hline
\end{tabular}

\section{Ibuprofen}

(RS)-2-(4-(2-methylpropyl)phenyl)propanoic acid Appearance: a white to off-white crystalline powder Molecular weight: 206.3

Solubility: practically insoluble in water, very soluble in alcohol and acetone, Chloroform, methyl alcohol, slightly soluble in ethyl acetate.

Indication: anti-inflammatory [23]<smiles>CC(C)Cc1ccc(C(C)C(=O)O)cc1</smiles>

$\log P: 3.6$ [28]

Solubility in PBS (pH 7.4): $25.16 \mathrm{mcg} / \mathrm{mL}$ [29]

\section{PEG-300}

Monomer: ethylene oxide

Molecular weight: 285-315

Application: cosolvent<smiles>CC(C)CCC(C)(C)O</smiles>

\section{Mannitol}

(2R,3R,4R,5R)-hexan-1,2,3,4,5,6-hexol

Application: converting the drug nanosuspensions to a stable solid form and easy redispersibility<smiles>OC[C@@H](O)C(O)[C@H](O)CO</smiles>

HPMC

Molecular weight: 86000

Specifications: improving the wettability, dissolution rate, and crystal inhibitor $[18,19,27]$

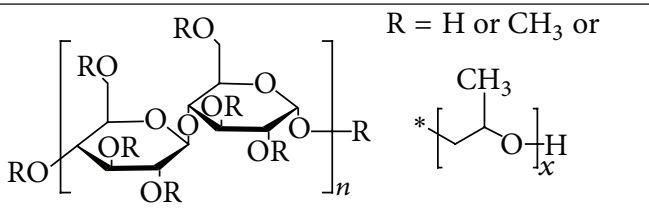


TABLE 2: Amount of polymers used in nanosuspension formulations.

\begin{tabular}{cccc}
\hline Drug & Sample label & $\begin{array}{c}\text { Organic phase } \\
\text { PEG-300 } \\
(\mathrm{wt} \%)\end{array}$ & $\begin{array}{c}\text { Aqueous phase } \\
\text { HPMC/PVP } \\
\text { (ratio 1:1) (wt } \%)\end{array}$ \\
\hline \multirow{4}{*}{ NIF } & $\mathrm{A}_{1}$ & 43.36 & 4.32 \\
& $\mathrm{~A}_{2}$ & 31.16 & 31.2 \\
& $\mathrm{~A}_{3}$ & 23.77 & 47.54 \\
& $\mathrm{~A}_{4}$ & 16.11 & 64.44 \\
\hline \multirow{4}{*}{$\mathrm{CBZ}$} & $\mathrm{A}_{1}$ & 42.01 & 4.2 \\
& $\mathrm{~A}_{2}$ & 30.48 & 30.5 \\
& $\mathrm{~A}_{3}$ & 23.36 & 46.72 \\
& $\mathrm{~A}_{4}$ & 15.92 & 63.68 \\
\hline \multirow{3}{*}{$\mathrm{IBP}$} & $\mathrm{A}_{1}$ & 42.01 & 4.2 \\
& $\mathrm{~A}_{2}$ & 30.48 & 30.5 \\
& $\mathrm{~A}_{3}$ & 23.36 & 46.72 \\
& $\mathrm{~A}_{4}$ & 15.92 & 63.68 \\
\hline
\end{tabular}

\section{Results and Discussion}

3.1. Lyophilization and Redispersibility of Nanoparticles. To remove water from the nanoparticle system, freeze drying, also known as lyophilization, was employed. The basic principle of freeze drying is to remove water from a frozen sample by sublimation and desorption under vacuum [32, 33]. However, the process generates various stresses which destabilise nanoparticles. In order to protect the particles from freezing and desiccation stresses, cryoprotectants or lyoprotectants are incorporated into the formulation before freeze drying. Freeze drying is generally carried out below the $T_{c}$ temperature. $T_{c}$ can be defined as collapse temperature in which the particles cannot maintain their microscopic structure. Hence, nanoparticles have the chance to immobilize within the glassy matrix of the cryoprotectants [34].

Lyophilization helps in converting a nanosuspension formulation, that is, liquid dispersion into a solid form which can be reconstituted prior to use. Nanosuspension formulations were lyophilized using mannitol as cryoprotectant at a constant concentration level $(10 \% \mathrm{w} / \mathrm{v})$. Mannitol acts as a carrier which prevents nanoparticle aggregation during the freeze drying process. Figure 1 shows the nanosuspension samples with and without mannitol. Freeze dried nanosuspensions without mannitol appeared as off-white fluffy and sheet-like materials and large aggregates were also observed. Nanosuspensions with mannitol formed a powder easily redispersible in PBS after manual shaking.

3.2. Particle Size and Size Distribution. The effect of the polymer : drug ratio on the size of the nanoparticles was studied using four different batches $A_{1}, A_{2}, A_{3}$, and $A_{4}$. The mean particle size for all different drug formulations (NIF, CBZ, and IBU) varied in the range from $426.4 \mathrm{~nm}$ to $995.4 \mathrm{~nm}$. The mean PDI values for all formulations varied in the range of 0.4 to 0.687 . It is inferred from the results that the polymer and drug type have significant effect on the particle size. This could be explained by the interaction of PVP with HPMC in aqueous media. The interaction between the methoxy and hydroxypropoxy groups of HPMC with carbonyl group of PVP creates a hydrogen bonding layer which covers the drug particles [35]. Hence hydrogen bonding prevents or retards crystal growth which results in smaller particle size. The other possible reason could be due to a specific drug-polymer interaction which forms compacted structure at higher polymer concentrations. Figure 2(a) shows that the particle size decreases with increasing the amount of polymers. The particle size of CBZ and IBU in nanosuspension formulations did not show any significant indication regarding the polymer ratio (Figures 2(b) and 2(c)) due to no significant drugpolymer interaction to form a compacted structure.

3.3. In Vitro Drug Dissolution Studies. Several formulations (as shown in Table 2) were prepared to evaluate the effect of the polymer: drug ratio on the drug dissolution profiles. The percentage release of pure drugs and drugs in polymer matrix as a function of time is presented in Figure 3 for the NIF (a), IBU (b), and CBZ (c). It can be seen that solubility of model drugs from the polymer matrix in PBS $(\mathrm{PH}=7.4)$ at $37^{\circ} \mathrm{C} \pm 0.5^{\circ} \mathrm{C}$ is higher than that of pure drugs. The data shows that the dissolution of NIF and IBU in the highest concentration of polymer matrix increased approximately 37 and 2 times, respectively, in comparison with the pure drug. Figure 3(c) shows that in the case of CBZ there was only a moderate increase in dissolution (1.2 times) at the highest concentration of polymers used. The general trend is that the extent of dissolution increases with increasing polymers content (Figure 3). Figure 4 illustrates that incorporation of polymers in the formulations has direct influence on the drug release profile compared to pure drug. Possible reasons for increased dissolution of drug nanosuspensions are (a) smaller drug particles in nanosuspension formulation compared to pure drugs, (b) interaction of HPMC and PVP as crystal growth inhibitor of drugs particles, (c) adsorption of drugs on the carriers which leads to increased surface area [36] and (d) methoxy and hydroxypropoxy groups of HPMC with carbonyl group of PVP form a hydrogen bonding with the molecules of drugs, that is, molecular complex formation, which results in improvement of dissolution of model drugs. In addition, the other advantage of using HPMC in the formulation is formation a gel around the particles which forms a barrier against diffusion of the dissolved drugs into dissolution medium and hence controls the release [22].

3.4. Kinetics of Drug Release. The in vitro dissolution data were fitted by various kinetic models; the release constants and regression coefficients $\left(R^{2}\right)$ are shown in Table 3 . Among the models tested, for the first 2 hours, the drug release profiles for NIF batch $\mathrm{A}_{4}$ were best fitted by zero-order kinetics based on the regression coefficient $\left(R^{2}\right)$ of 0.9858 . Release of the constant amount of drug in specific time points characterises zero order kinetics. The zero-order process indicates that the drug release mechanism is not dependent on the drug concentration $[37,38]$. The Hixson-Crowell model which plots the cube root of cumulative percentage of 


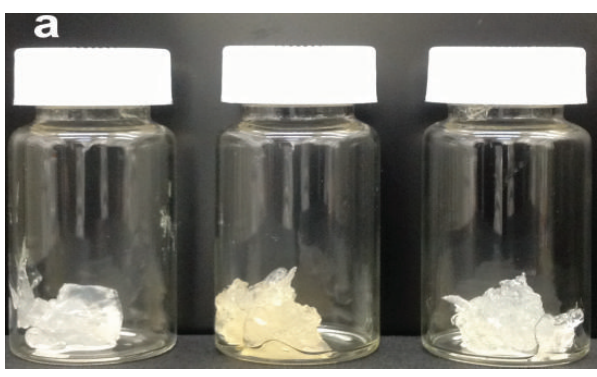

(a)

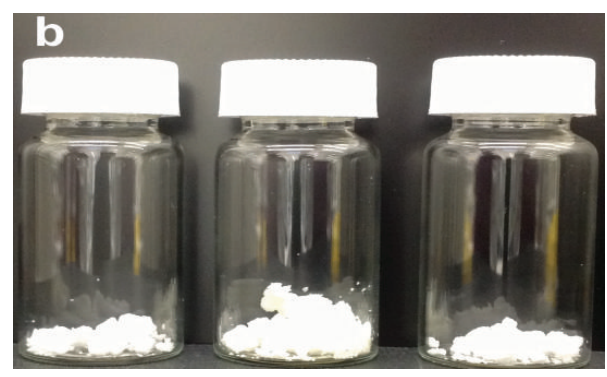

(b)

Figure 1: Physical state of drugs nanosuspensions without mannitol (a) and with mannitol (b).

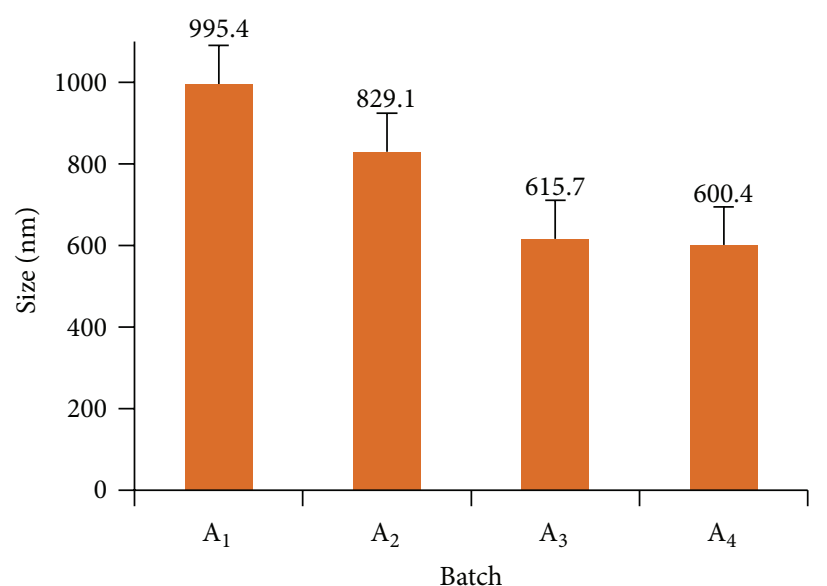

(a)

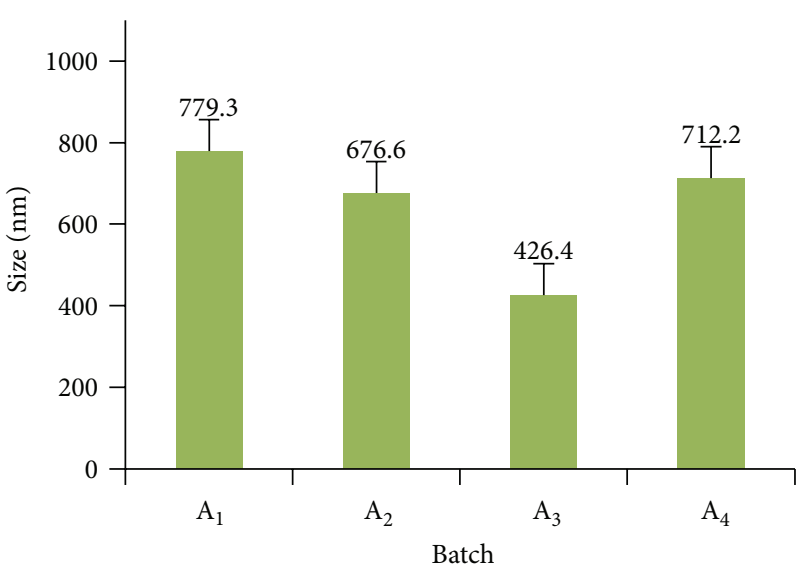

(b)

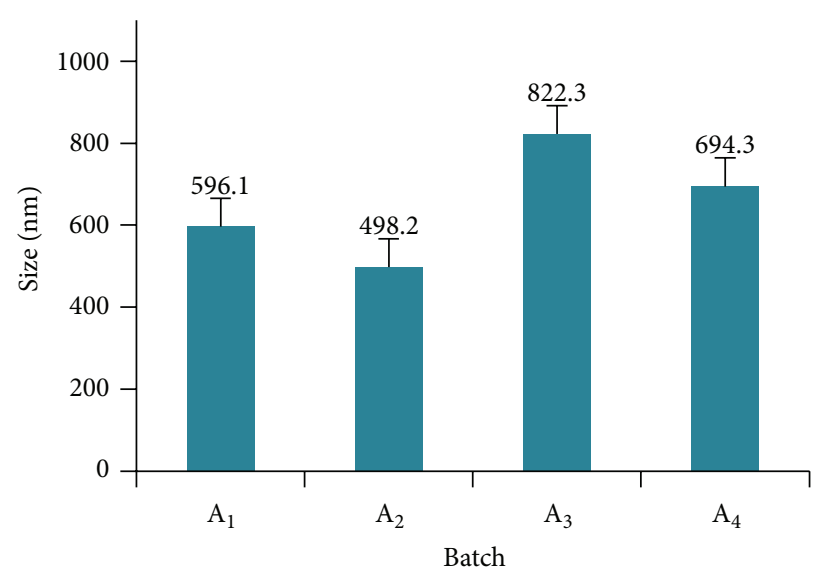

(c)

FIGURE 2: Comparison between size and polymer ratio: $\operatorname{NIF~(a),~CBZ~(b),~and~IBU~(C)~}(n=3)$.

drug release versus the time showed an excellent fit for the batch $\mathrm{A}_{4}$ of IBU $\left(R^{2}: 0.9984\right)$. The Hixson-Crowell kinetics describes drug release from systems where there is a change in surface area and diameter of particles $[39,40]$. For different CBZ nanosuspensions, no strong indication of fitting was observed. $R^{2}$ value for batches $\mathrm{A}_{2}, \mathrm{~A}_{3}$, and $\mathrm{A}_{4}$ of $\mathrm{CBZ}$ was between 0.6836 and 0.8082 .
3.5. Differential Scanning Calorimetry (DSC) Studies. Figure 5 shows the DSC curves for pure drugs (NIF, CBZ, and IBU) and drug nanosuspensions with different polymer content. Pure nifedipine, carbamazepine, and ibuprofen exhibit a sharp melting endotherm peaks at $174.76^{\circ} \mathrm{C}$, $192.65^{\circ} \mathrm{C}$, and $74.77^{\circ} \mathrm{C}$, respectively, and corresponding to their melting points and crystalline nature [23]. Figure 5 
NIF

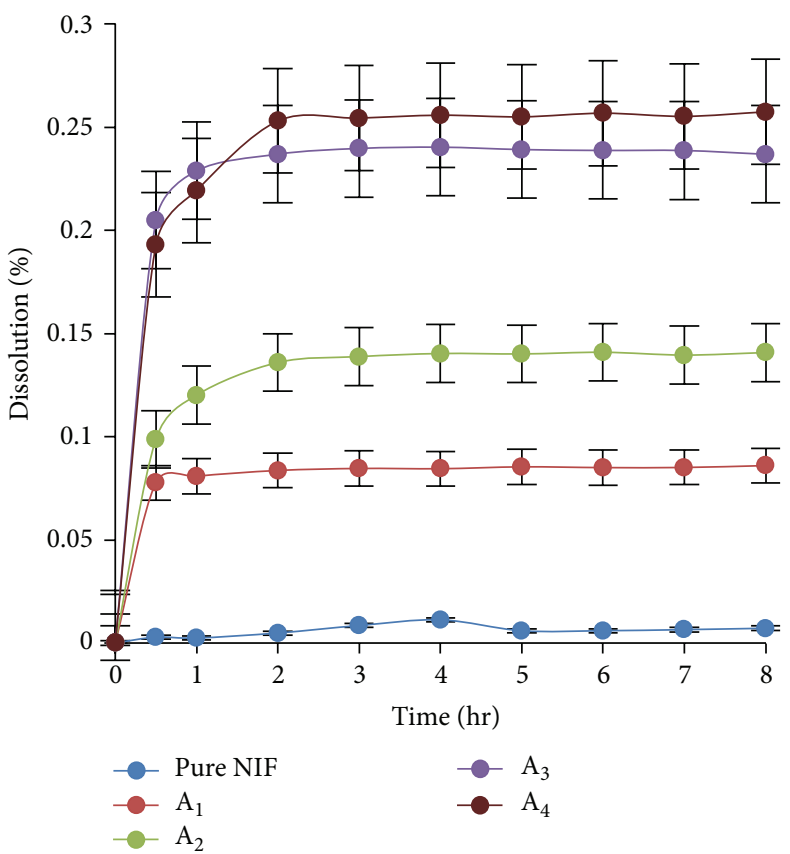

(a)
IBU

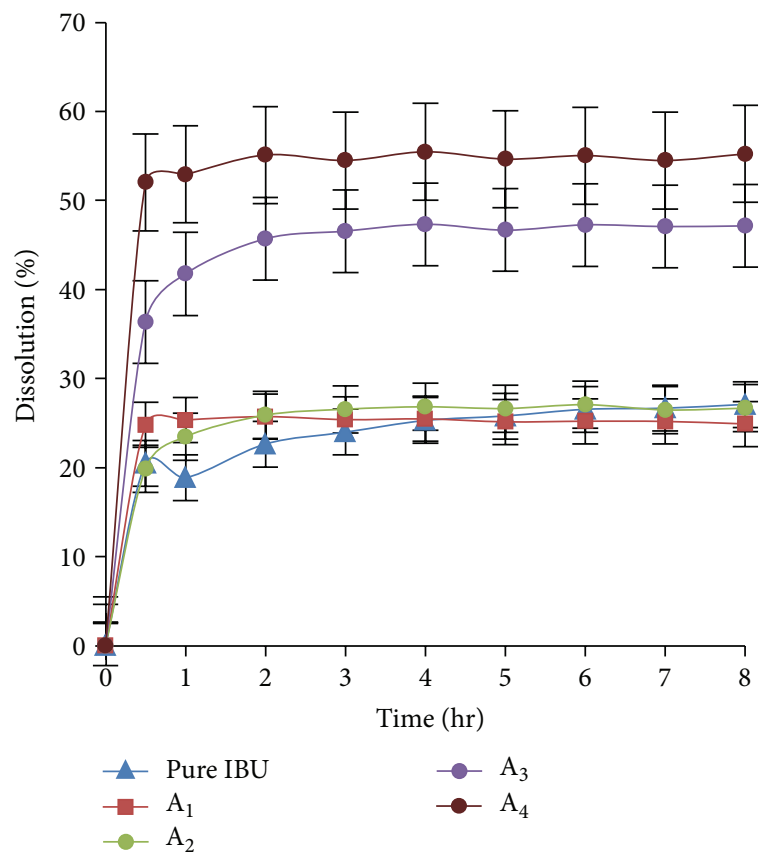

(b)

CBZ

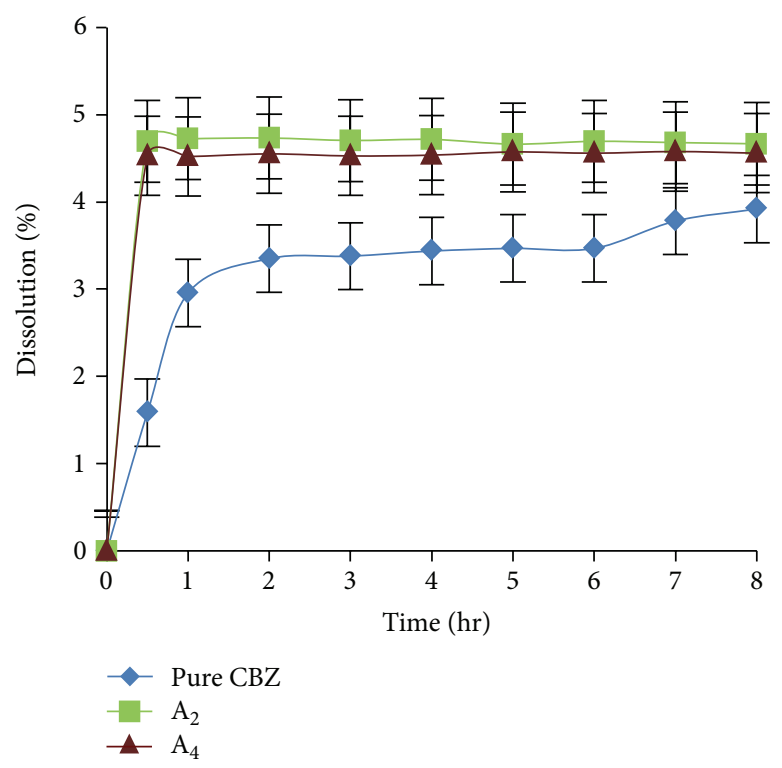

(c)

FIGURE 3: In vitro release of NIF (a), IBU (b), and CBZ (c) nanosuspensions in phosphate buffer $\mathrm{PH}=7.4$ at $37^{\circ} \mathrm{C} \pm 0.5^{\circ} \mathrm{C}(n=3)$.

shows that formulations with higher concentration of polymers display lower enthalpy and melting temperature. The reason for such behaviour is polymers-drug interaction which prevents drug particles from rearranging within the polymer network. Figure 5 shows that the drug-free sample (carrier) prepared by the same method (co-solvent method) exhibited two broad melting endotherm peaks at $87.74^{\circ} \mathrm{C}$ and $159.74^{\circ} \mathrm{C}$. The endotherm peaks indicate the partial crystallinity of the carrier. The endotherms peaks of NIF,
CBZ, and IBU nanosuspension formulations are presented in the Table 4. No endotherm peaks corresponding to the melting points of pure crystalline nifedipine, carbamazepine, or ibuprofen were observed. Similar behaviour has been reported for the triamterene in Gelucire 44/14 and PEG [41], cinnarizine in Gelucire 53/10 [42], and paracetamol in PEG 4000 [43]. Hence, the DSC results suggest that drugs progressively dissolved in the polymer matrix upon heating during the DSC measurements. Craig [44] has 


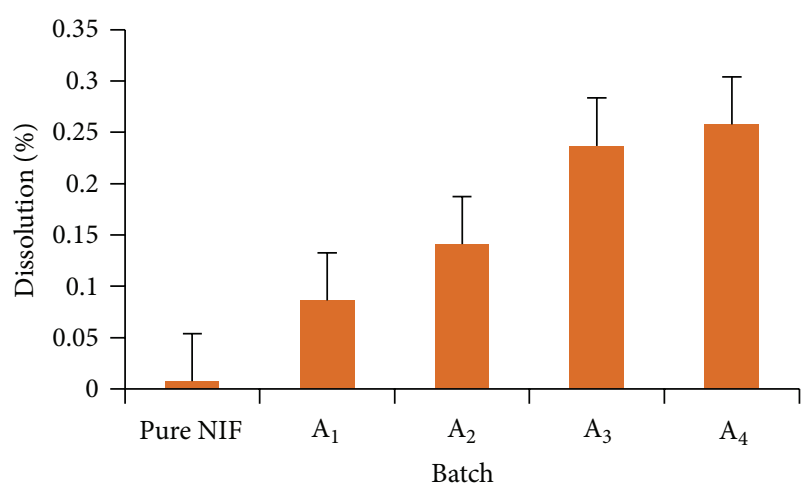

(a)

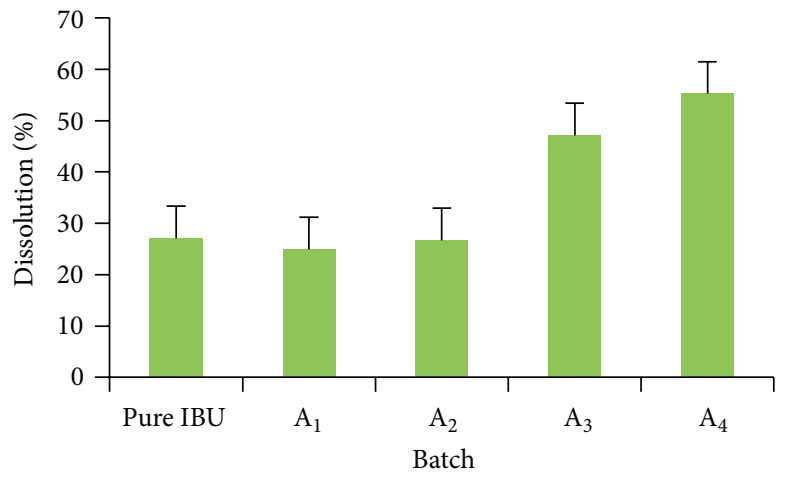

(b)

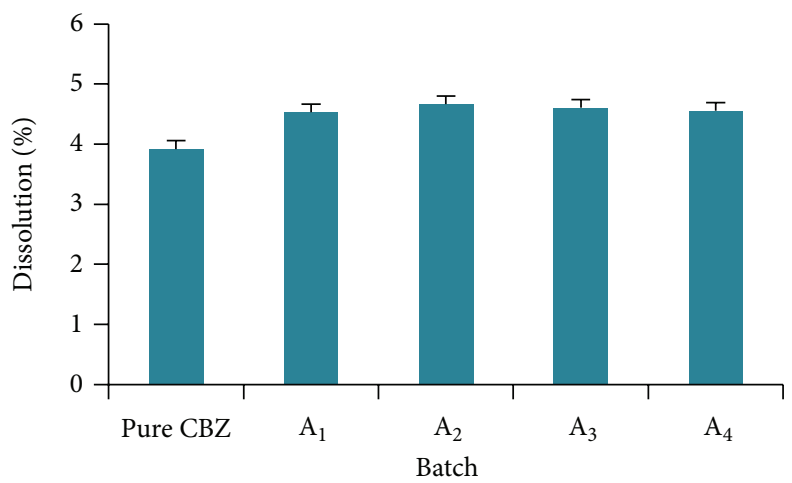

(c)

Figure 4: Comparison of the dissolution for NIF (a), IBU (b), and CBZ (c) in form of pure drug and nanosuspensions $(n=3)$.

TABLE 3: Kinetic release rate constants and correlation coefficients of various kinetic models (first 2 hours).

\begin{tabular}{|c|c|c|c|c|c|c|c|}
\hline \multirow{2}{*}{ Drug } & \multirow{2}{*}{ Sample label } & \multicolumn{2}{|c|}{ Zero order } & \multicolumn{2}{|c|}{ First order } & \multicolumn{2}{|c|}{ Hixson-Crowell } \\
\hline & & $K_{0}$ & $R^{2}$ & $K_{1}$ & $R^{2}$ & $K_{2}$ & $R^{2}$ \\
\hline \multirow{4}{*}{ NIF } & $A_{1}$ & 0.0038 & 0.9500 & 0.0471 & 0.9453 & 0.0068 & 0.9469 \\
\hline & $\mathrm{A}_{2}$ & 0.0235 & 0.9260 & 0.2001 & 0.9015 & 0.0325 & 0.9099 \\
\hline & $\mathrm{A}_{3}$ & 0.0195 & 0.7963 & 0.0881 & 0.7847 & 0.0177 & 0.7885 \\
\hline & $\mathrm{A}_{4}$ & 0.0392 & 0.9858 & 0.1754 & 0.9751 & 0.0353 & 0.9790 \\
\hline \multirow{4}{*}{ CBZ } & $\mathrm{A}_{1}$ & 0.0045 & 0.0262 & 0.0010 & 0.0263 & 0.0005 & 0.0262 \\
\hline & $\mathrm{A}_{2}$ & 0.0214 & 0.8082 & 0.0045 & 0.8076 & 0.0025 & 0.8078 \\
\hline & $\mathrm{A}_{3}$ & 0.0064 & 0.7631 & 0.0014 & 0.7630 & 0.0008 & 0.7630 \\
\hline & $\mathrm{A}_{4}$ & 0.0171 & 0.6843 & 0.0038 & 0.6836 & 0.0020 & 0.6838 \\
\hline \multirow{4}{*}{ IBU } & $\mathrm{A}_{1}$ & 0.5817 & 0.9195 & 0.0230 & 0.9167 & 0.0220 & 0.9176 \\
\hline & $\mathrm{A}_{2}$ & 3.7847 & 0.9115 & 0.0230 & 0.9167 & 0.1531 & 0.8975 \\
\hline & $\mathrm{A}_{3}$ & 5.9004 & 0.9240 & 0.1435 & 0.9065 & 0.1614 & 0.9125 \\
\hline & $\mathrm{A}_{4}$ & 2.0760 & 0.9978 & 0.0387 & 0.9982 & 0.0475 & 0.9984 \\
\hline
\end{tabular}

previously suggested that the drug may be dissolved in the molten polymer, such as PEG, over a wide range of temperatures. The characteristic DSC peak of the carrier matrix without endothermic peaks due to drug melting indicates that the drugs were dissolved in the molten carrier during the measurements. The DSC and dissolution data indicate that in the presence of polymers, the drugs were subsequently transformed into their amorphous or molecular forms.

\section{Conclusion}

The potential of NIF, CBZ, and IBU nanosuspensions for increasing the dissolution rate and extent was demonstrated. 


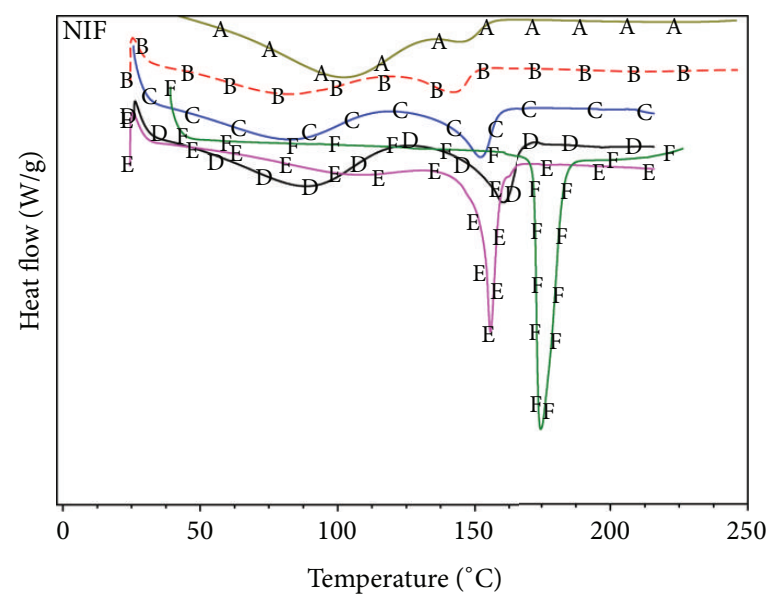

(a)

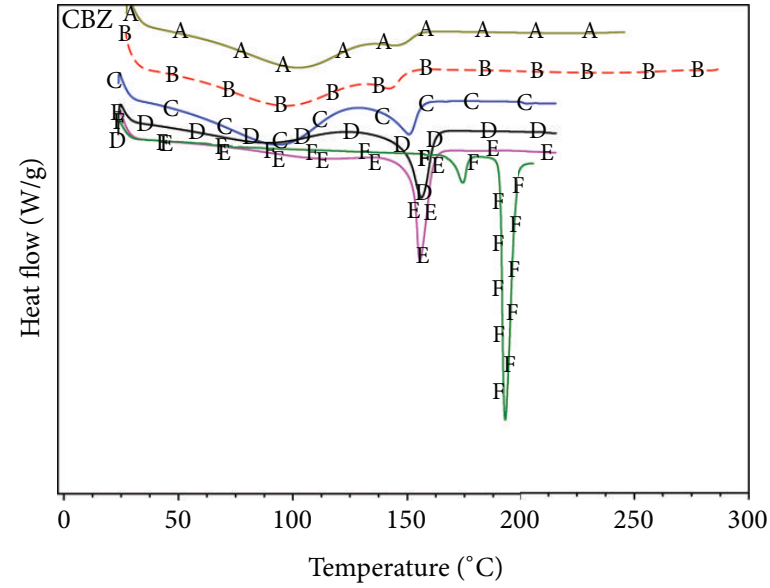

(b)

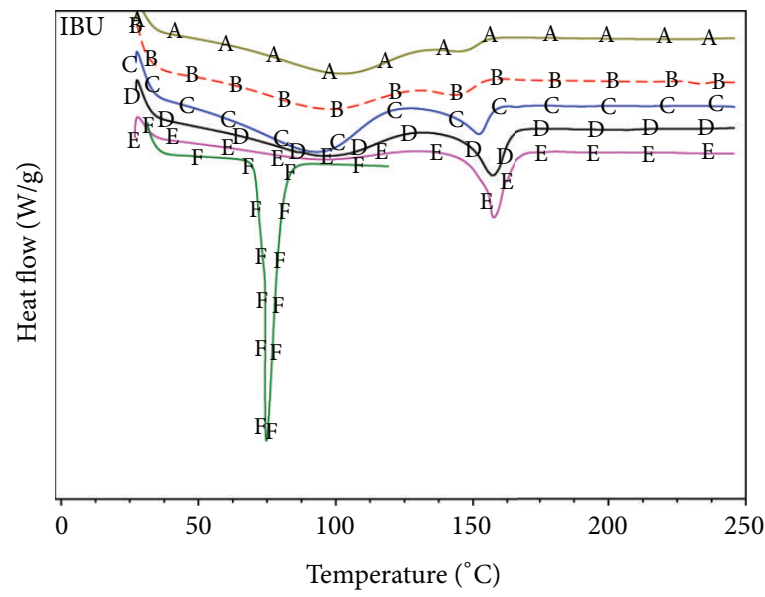

(c)

FiguRE 5: DSC thermoghrams of NIF, CBZ, and IBU: pure drug (F), nanosuspension formulations: batch $A_{1}(E)$, batch $A_{2}(D)$, batch $A_{3}(C)$, batch $\mathrm{A}_{4}(\mathrm{~B})$, and carrier $(\mathrm{A})$ (the spectra are offset in vertical direction for clarification).

TABLE 4: Heat flow and endothermic peaks of drug formulations obtained from DSC measurements.

\begin{tabular}{cccc}
\hline \multicolumn{2}{c}{ Drug Sample label } & Heat flow $(\mathrm{W} / \mathrm{g})$ & Endotherm peaks $\left({ }^{\circ} \mathrm{C}\right)$ \\
\hline \multirow{4}{*}{ NIF } & $\mathrm{A}_{1}$ & -2.435 & 155.69 \\
& $\mathrm{~A}_{2}$ & -1.049 and -1.216 & 88.93 and 160.46 \\
& $\mathrm{~A}_{3}$ & -0.8706 and -1.053 & 83.45 and 152.11 \\
& $\mathrm{~A}_{4}$ & -0.804 and -0.7874 & 82.97 and 142.82 \\
\hline \multirow{4}{*}{$\mathrm{CBZ}$} & $\mathrm{A}_{1}$ & -2.473 & 155.69 \\
& $\mathrm{~A}_{2}$ & -0.867 and -1.765 & 89.41 and 156.17 \\
& $\mathrm{~A}_{3}$ & -1.298 and -1.125 & 93.70 and 150.68 \\
& $\mathrm{~A}_{4}$ & -1.152 and -0.8744 & 97.56 and 143.05 \\
\hline \multirow{4}{*}{$\mathrm{IBP}$} & $\mathrm{A}_{1}$ & -1.69 & 157.60 \\
& $\mathrm{~A}_{2}$ & -1.082 and -1.404 & 96.80 and 157.36 \\
& $\mathrm{~A}_{3}$ & -1.318 and -1.024 & 93.22 and 152.35 \\
& $\mathrm{~A}_{4}$ & -1.115 and -0.8825 & 98.47 and 145.20 \\
\hline
\end{tabular}

Nanosuspensions were prepared by the cosolvent technique which is a simple method without the need for any complicated instruments. Due to formation of nanosuspensions, the dissolution rates of drugs were increased in comparison with the pure drugs. The results also showed that extent of dissolution of the drugs from polymer matrix was affected by changing the drug: polymer (HPMC \& PVP) ratio and the highest dissolution of NIF (0.26\%), CBZ (4.56\%), and IBU (55.24\%) were observed at the highest concentrations of polymers (batch $\mathrm{A}_{4}$ ). The results of DSC studies demonstrated that amorphous fractions of model drugs NIF, CBZ, and IBU increase upon increasing polymer level in the nanosuspension formulations. The results confirmed that the co-solvent technique can be used to prepare drug nanosuspensions using HPMC and PVP as carriers as a means of increasing the dissolution rates.

\section{References}

[1] X. Pu, J. Sun, M. Li, and Z. He, "Formulation of nanosuspensions as a new approach for the delivery of poorly soluble drugs," Current Nanoscience, vol. 5, no. 4, pp. 417-427, 2009.

[2] H. Chen, C. Khemtong, X. Yang, X. Chang, and J. Gao, "Nanonization strategies for poorly water-soluble drugs," Drug Discovery Today, vol. 16, no. 7-8, pp. 354-360, 2011. 
[3] Y. Kawabata, K. Wada, M. Nakatani, S. Yamada, and S. Onoue, "Formulation design for poorly water-soluble drugs based on biopharmaceutics classification system: basic approaches and practical applications," International Journal of Pharmaceutics, vol. 420, no. 1, pp. 1-10, 2011.

[4] R. H. Muller, R. Becker, B. Kruss, and K. Peters, "Pharmaceutical nanosuspensions for medicament administration as systems with increased saturation solubility and rate of solution," US Patent 5858410, 1999, http://www.google. com.au/patents/US5858410.

[5] G. Pifferi and P. Restani, "The safety of pharmaceutical excipients," Farmaco, vol. 58, no. 8, pp. 541-550, 2003.

[6] G. C. S. Rao, M. S. Kumar, N. Mathivanan, and M. E. B. Rao, "Nanosuspensions as the most promising approach in nanoparticulate drug delivery systems," Pharmazie, vol. 59, no. 1, pp. 5-9, 2004.

[7] V. B. Patravale, A. A. Date, and R. M. Kulkarni, "Nanosuspensions: a promising drug delivery strategy," Journal of Pharmacy and Pharmacology, vol. 56, no. 7, pp. 827-840, 2004.

[8] R. O. Williams III, A. B. Watts, and D. A. Miller, Formulating Poorly Water Soluble Drugs, Springer, New York, NY, USA, 2012.

[9] V. Kharb, M. Bhatia, H. Dureja, and D. Kaushik, "Nanoparticle technology for the delivery of poorly water-soluble drugs," Pharmaceutical Technology, vol. 30, no. 2, pp. 82-92, 2006.

[10] C. M. Keck and R. H. Müller, "Drug nanocrystals of poorly soluble drugs produced by high pressure homogenisation," European Journal of Pharmaceutics and Biopharmaceutics, vol. 62, no. 1, pp. 3-16, 2006.

[11] K. Moser, K. Kriwet, Y. N. Kalia, and R. H. Guy, "Stabilization of supersaturated solutions of a lipophilic drug for dermal delivery," International Journal of Pharmaceutics, vol. 224, no. 1-2, pp. 169-176, 2001.

[12] S. L. Raghavan, A. Trividic, A. F. Davis, and J. Hadgraft, "Crystallization of hydrocortisone acetate: influence of polymers," International Journal of Pharmaceutics, vol. 212, no. 2, pp. 213221, 2001.

[13] S. L. Raghavan, K. Schuessel, A. Davis, and J. Hadgraft, "Formation and stabilisation of triclosan colloidal suspensions using supersaturated systems," International Journal of Pharmaceutics, vol. 261, no. 1-2, pp. 153-158, 2003.

[14] R. G. Strickley, "Solubilizing excipients in oral and injectable formulations," Pharmaceutical Research, vol. 21, no. 2, pp. 201230, 2004.

[15] U. Kumprakob, J. Kawakami, and I. Adachi, "Permeation enhancement of ketoprofen using a supersaturated system with antinucleant polymers," Biological and Pharmaceutical Bulletin, vol. 28, no. 9, pp. 1684-1688, 2005.

[16] M. C. Lamas, L. Villaggi, I. Nocito et al., "Development of parenteral formulations and evaluation of the biological activity of the trypanocide drug benznidazole," International Journal of Pharmaceutics, vol. 307, no. 2, pp. 239-243, 2006.

[17] N. Leveque, S. L. Raghavan, M. E. Lane, and J. Hadgraft, "Use of a molecular form technique for the penetration of supersaturated solutions of salicylic acid across silicone membranes and human skin in vitro," International Journal of Pharmaceutics, vol. 318, no. 1-2, pp. 49-54, 2006.

[18] M. Iervolino, B. Cappello, S. L. Raghavan, and J. Hadgraft, "Penetration enhancement of ibuprofen from supersaturated solutions through human skin," International Journal of Pharmaceutics, vol. 212, no. 1, pp. 131-141, 2001.
[19] M. Iervolino, S. L. Raghavan, and J. Hadgraft, "Membrane penetration enhancement of ibuprofen using supersaturation," International Journal of Pharmaceutics, vol. 198, no. 2, pp. 229238, 2000.

[20] R. Nair, S. Gonen, and S. W. Hoag, "Influence of polyethylene glycol and povidone on the polymorphic transformation and solubility of carbamazepine," International Journal of Pharmaceutics, vol. 240, no. 1-2, pp. 11-22, 2002.

[21] H. Sekikawa, M. Nakano, and T. Arita, "Inhibitory effect of polyvinylpyrrolidone on the crystallization of drugs," Chemical and Pharmaceutical Bulletin, vol. 26, no. 1, pp. 118-126, 1978.

[22] E. Karavas, E. Georgarakis, and D. Bikiaris, "Application of PVP/HPMC miscible blends with enhanced mucoadhesive properties for adjusting drug release in predictable pulsatile chronotherapeutics," European Journal of Pharmaceutics and Biopharmaceutics, vol. 64, no. 1, pp. 115-126, 2006.

[23] S. C. Sweetman, Martindale: The Complete Drug Reference, Pharmaceutical Press, 2007.

[24] C. Jamaty, B. Bailey, A. Larocque, E. Notebaert, K. Sanogo, and J. M. Chauny, "Lipid emulsions in the treatment of acute poisoning: a systematic review of human and animal studies," Clinical Toxicology, vol. 48, no. 1, pp. 1-27, 2010.

[25] S. L. Ali and K. Florey, Analytical Profiles of Drug Substances, Academic Press, San Diego, Calif, USA, 1989.

[26] A. F. El-Kattan, C. S. Asbill, N. Kim, and B. B. Michniak, "The effects of terpene enhancers on the percutaneous permeation of drugs with different lipophilicities," International Journal of Pharmaceutics, vol. 215, no. 1-2, pp. 229-240, 2001.

[27] C. Leuner and J. Dressman, "Improving drug solubility for oral delivery using solid dispersions," European Journal of Pharmaceutics and Biopharmaceutics, vol. 50, no. 1, pp. 47-60, 2000.

[28] P. K. Lakshmi, M. K. Kumar, A. Sridharan, and S. Bhaskaran, "Formulation and evaluation of ibuprofen topical gel: a novel approach for penetration enhancement," International Journal of Applied Pharmaceutics, vol. 3, no. 3, pp. 25-30, 2011.

[29] A. Nayak and A. Jain, "In vitro and in vivo study of poly(ethylene glycol) conjugated ibuprofen to extend the duration of action," Scientia Pharmaceutica, vol. 79, no. 2, pp. 359373, 2011.

[30] A. F. Davis and J. Hadgraft, "Effect of supersaturation on membrane transport: 1. Hydrocortisone acetate," International Journal of Pharmaceutics, vol. 76, no. 1-2, pp. 1-8, 1991.

[31] P. Costa and J. M. S. Lobo, "Modeling and comparison of dissolution profiles," European Journal of Pharmaceutical Sciences, vol. 13, no. 2, pp. 123-133, 2001.

[32] N. A. Williams and G. P. Polli, "The lyophilization of pharmaceuticals: a literature review," Journal of Parenteral Science and Technology, vol. 38, no. 2, pp. 48-60, 1984.

[33] M. J. Pikal, S. Shah, M. L. Roy, and R. Putman, “The secondary drying stage of freeze drying: drying kinetics as a function of temperature and chamber pressure," International Journal of Pharmaceutics, vol. 60, no. 3, pp. 203-207, 1990.

[34] X. Tang and M. J. Pikal, "Design of freeze-drying processes for pharmaceuticals: practical advice," Pharmaceutical Research, vol. 21, no. 2, pp. 191-200, 2004.

[35] N. Nyamweya and S. W. Hoag, "Assessment of polymer-polymer interactions in blends of HPMC and film forming polymers by modulated temperature differential scanning calorimetry," Pharmaceutical Research, vol. 17, no. 5, pp. 625-631, 2000. 
[36] Y. Javadzadeh, B. Jafari-Navimipour, and A. Nokhodchi, "Liquisolid technique for dissolution rate enhancement of a high dose water-insoluble drug (carbamazepine)," International Journal of Pharmaceutics, vol. 341, no. 1-2, pp. 26-34, 2007.

[37] T. Chatzaeiaoannou, Quantitative Calculations in Pharmaceutical Practice and Research, VCH Publishers, New York, NY, USA, 1993.

[38] M. H. Shoaib, J. Tazeen, H. A. Merchant, and R. I. Yousuf, "Evaluation of drug release kinetics from ibuprofen matrix tablets using HPMC," Pakistan Journal of Pharmaceutical Sciences, vol. 19, no. 2, pp. 119-124, 2006.

[39] S. Dash, P. N. Murthy, L. Nath, and P. Chowdhury, "Kinetic modeling on drug release from controlled drug delivery systems," Acta Poloniae Pharmaceutica, vol. 67, no. 3, pp. 217-223, 2010.

[40] A. Hixson and J. Crowell, "Dependence of reaction velocity upon surface and agitation," Industrial and Engineering Chemistry, vol. 23, no. 8, pp. 923-931, 1931.

[41] S. K. Dordunoo, J. L. Ford, and M. H. Rubinstein, "Preformulation studies on solid dispersions containing triamterene or temazepam in polyethylene glycols or gelucire 44/14 for liquid filling of hard gelatin capsules," Drug Development and Industrial Pharmacy, vol. 17, no. 12, pp. 1685-1713, 1991.

[42] J. M. Ginés, M. D. Veiga, M. J. Arias, and A. M. Rabasco, "Elaboration and thermal study of interactions between cinnarizine and gelucire 53/10 physical mixtures and solid dispersions," International Journal of Pharmaceutics, vol. 126, no. 1-2, pp. 287291, 1995.

[43] G. R. Lloyd, D. Q. M. Craig, and A. Smith, "An investigation into the melting behavior of binary mixes and solid dispersions of paracetamol and PEG 4000," Journal of Pharmaceutical Sciences, vol. 86, no. 9, pp. 991-996, 1997.

[44] D. Q. M. Craig, "Polyethylene glycols and drug release," Drug Development and Industrial Pharmacy, vol. 16, no. 17, pp. 25012526, 1990. 

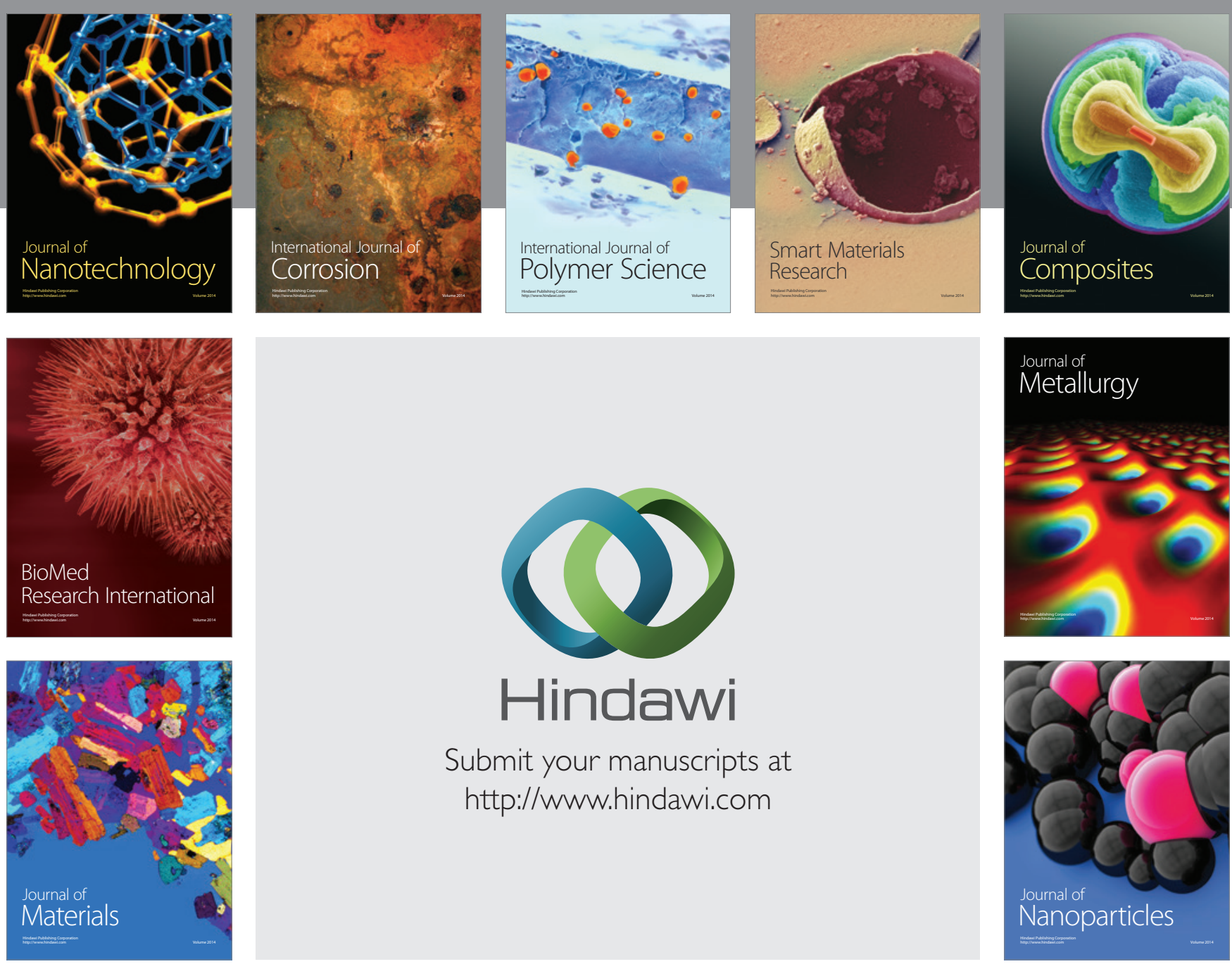

Submit your manuscripts at http://www.hindawi.com
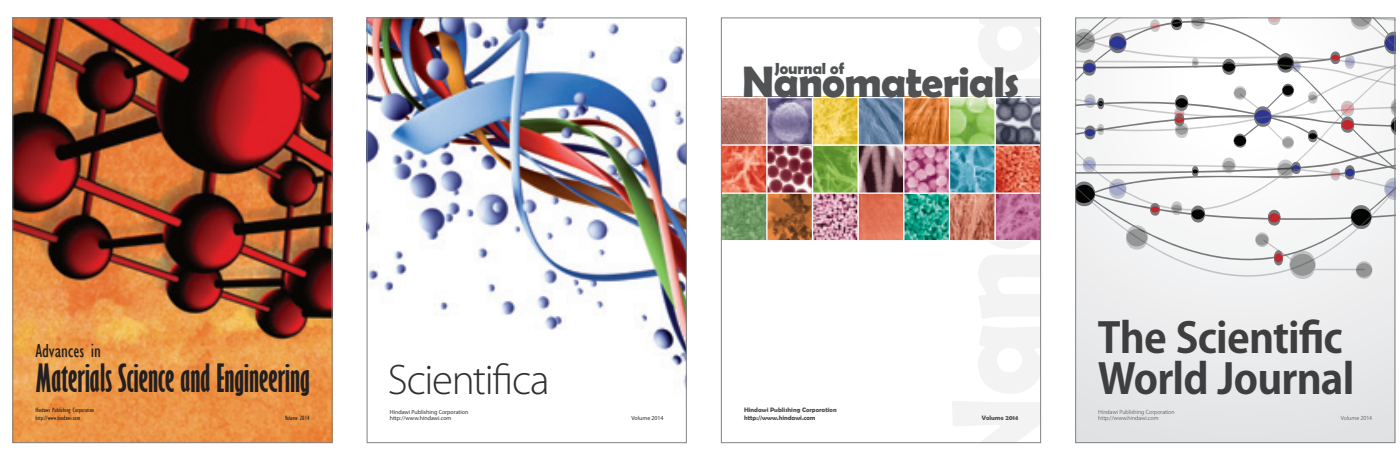

\section{The Scientific World Journal}
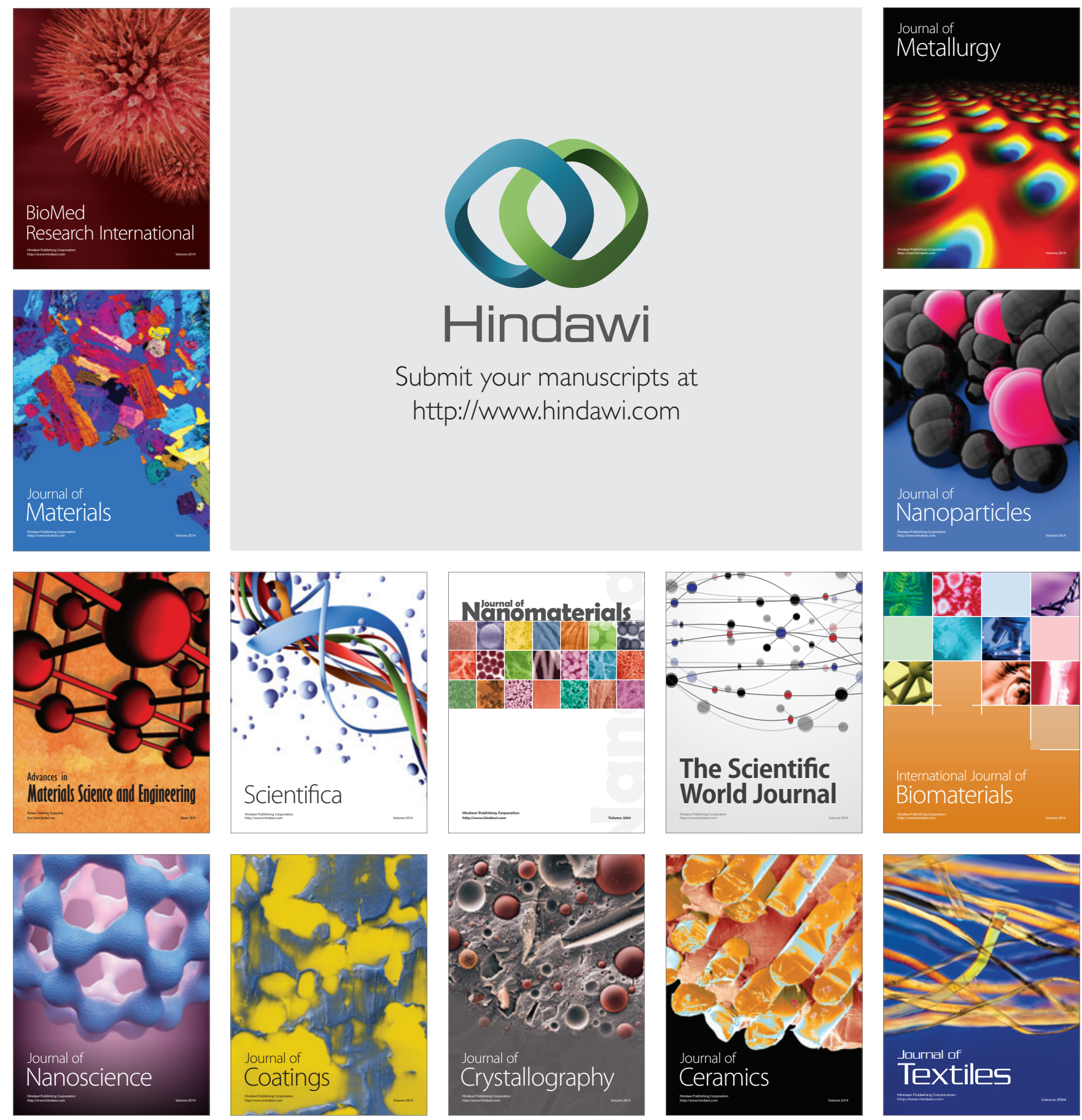